Research Article

\title{
In Situ Curing of a Polymer Film for Light-Proof Coring of Deep Rocks with Preservation of Rock Quality and Moisture
}

\author{
Zhiyu Zhao $\mathbb{D}^{1},{ }^{1}$ Heping Xie, ${ }^{1,2}$ Tao Liu $\mathbb{D}^{\mathrm{D}},{ }^{1}$ and Yifan $\mathrm{Wu}\left(\mathbb{D}{ }^{1}\right.$ \\ ${ }^{1}$ Institute of New Energy and Low-Carbon Technology, Sichuan University, Chengdu 610065, China \\ ${ }^{2}$ Guangdong Provincial Key Laboratory of Deep Earth Sciences and Geothermal Energy Exploitation and Utilization, \\ Institute of Deep Earth Sciences and Green Energy, Shenzhen University, Shenzhen 518060, China \\ Correspondence should be addressed to Tao Liu; liutao3200023@scu.edu.cn
}

Received 12 August 2020; Revised 24 September 2020; Accepted 25 October 2020; Published 9 November 2020

Academic Editor: Fengqiang Gong

Copyright (C) 2020 Zhiyu Zhao et al. This is an open access article distributed under the Creative Commons Attribution License, which permits unrestricted use, distribution, and reproduction in any medium, provided the original work is properly cited.

\begin{abstract}
Deep in situ rock mechanic is of great significance for deep foundation research and engineering application. In order to explore the deep in situ mechanical law, it is necessary to maintain the in situ environment, which means to achieve fidelity coring. However, at present, there is a lack of method of deep rocks with quality-preserving, moisture-preserving, and light-proof to obtain deep rock specimens, making it difficult to obtain in situ scientific information of the core. In this study, we developed a novel in situ quality-preserving coring method of deep rocks based on an in situ film-forming process. In this method, a solution was covered on the core, and then a sealing polymer film was formed through crosslinking reaction. Organic montmorillonite and carbon black functional fillers were incorporated to further reduce the $\mathrm{O}_{2}$ and water vapor permeability and light transmittance of the polymer sealing film. The sealing film was characterized by Fourier transform infrared spectroscopy, X-ray diffraction, and scanning electron microscopy. Compared to the neat silicone rubber film, the $\mathrm{O}_{2}$ and water vapor permeability and light transmittance of the sealing film were reduced by $81.2 \%, 84.4 \%$, and $100 \%$, respectively. In addition, the mechanical and thermal stability of the sealing film was excellent; it showed an elongation at a break of $98.0 \%$ and a tensile strength of $0.857 \mathrm{MPa}$. Moreover, a simulator was developed and the sealing film showed an excellent quality-preserving ability on the rock specimens. The significant improvement demonstrated that the method developed in this research may open up new opportunities for the development of the in situ quality-preserving coring method of deep rocks and construction of deep in situ rock mechanics.
\end{abstract}

\section{Introduction}

With the shallow resources of the earth gradually exhausted and decreasing of conventional energy, deep exploration of energy has become necessity. [1]. In order to march deep into the earth, it is necessary to explore the physical and mechanical behaviours of rocks with different depths which is a significant guiding for engineering applications $[2,3]$. However, the current rock mechanic theories and methods, based on standard rock core, classic real-time load path, and elastoplastic constitutive relation, are not obtained under the fidelity conditions, which is difficult to effectively guide the basic research and engineering implementation of the exploration to the deep earth $[4,5]$. Therefore, constructing a deep in situ fidelity coring method to research the deep rock mechanic law in the deep in situ environment is urgent. The deep in situ rocks, with pore-water, pore pressure, temperature, various gas, mineral resources, and microorganisms, need to be treated with temperature-retained, pressure-retained, quality-preserved, moisture-preserved, and light-proof for fidelity coring. At present, scholars have carried out lots of research studies on coring with retaining of temperature and pressure and make an excellent progress, but coring with preservations of quality and moisture as well as light-proof is still a tough problem.

Deep geoscientific drilling has become an indispensable measurement method for the investigation of resources, disasters, and environments. Since the 1950s, several projects, such as the Mohole Drilling Project, Kontinentales Tiefbohr Programm, and International Continental 
Scientific Drilling Program, have been established worldwide [6-10]. However, the quality-preserving coring cannot be achieved by the traditional coring methods and devices, which leads to some problems. The information of hydrates, liquid phases, and microorganisms contained in deep rocks is distorted owing to the difficulty in maintaining the in situ temperature and pressure. Furthermore, the drilling fluid contaminates the specimens, which distorts the information of the pore pressure, temperature, humidity, and microbe activity. Moreover, most subpacking, sample preparation, and testing methods cannot preserve the state of the in situ core owing to the core exposure to the external environment after coring.

Gas hydrate coring, which has been investigated extensively [11], provides quantitative information while preserving the quality. Pressure Core Sampler (PCS) used in the Ocean Drilling Program (ODP) [12, 13], Fugro Pressure Corer (FPC), and HY-ACE Rotary Corer (HRC) used in the Hydrate Autoclave Coring Equipment System (HY-ACE) $[14,15]$ had a plastic core barrel to prevent core contamination by the drilling fluid, while the FPC and HRC integrated the piston structure to prevent pollution, which was beneficial for the discharge of seawater in the core barrel through the piston at the bottom of the core barrel after coring. Physical methods, e.g., applying special materials and adjusting the structure of the piston, can only reduce the influence of external factors on the in situ core, so internal information can still be lost. In addition, the Pressure Core Barrel (PCB) used in the Deep Sea Drilling Project (DSDP) [16] mainly used a nonaggressive colloidal sealing fluid of being difficult to prepare and remove [17], to fill the space between the coring device and the core to prevent the drilling fluid from contaminating the core; this fluid slowed down the diffusion of the internal information of the core to the outside but cannot completely stop the loss of gas phase information in the core.

Recently, Xie et al. [18, 19] proposed a coring method and technology that preserved the quality and moisture of specimens and blocked the light of external by applying a polymer composite film with sealing effect of preventing the exchange of matter between the core and outside of the specimen. However, it is difficult to coat the core during the dynamic process in a narrow space of coring casing. To solve this issue, a film-formation mechanism was developed by regulating the basic properties of the sealing film and controlling the film-formation process, where polymer composite material played a significant role in the qualitypreserving, moisture-preserving, and light-proof coring.

Silicone rubber has shown potential as a sealing material owing to its special film-formation mechanism and physicalchemical properties [20]. First, liquid silicone rubber can be transferred into a solid state triggered by water vapor and a catalyst, which is favorable for in situ film formation on the surface of the core filled with water. Bo [21] studied the kinetics of the crosslinking process of silicone rubber and determined the interrelation between the film-forming time and temperature and water vapor content. Second, the excellent properties of silicone rubber, such as compact microstructure, hydrophobicity, and thermal stability, can completely match the environment of the deep earth. Finally, layer-by-layer assembly [22], surface coating [23], and incorporation of two-dimensional (2D) nanosheets [24, 25] are efficient methods to improve the barrier properties of film. Ha et al. [26] strengthened the interaction between the modified GO and PDMS and reduced the gas permeability of the composite with $1 \mathrm{wt} \%$ GO by $45 \%$. Therefore, exploiting material-forming mechanisms appropriately, designing suitable film components, and improving their properties are important factors of using silicone rubber for deep in situ quality-preserving coring.

In this paper, we report a mechanism of in situ crosslinking and curing film-forming for deep in situ qualitypreserving, moisture-preserving, and light-proof coring of deep rocks. An elastic polymer was utilized as the matrix material. Organic montmorillonite (OMMT) and carbon black (CB) were used as functional fillers to improve the barrier properties of the sealing film, and a catalyst was used to speed up the crosslinking process. This material combination led to the following exceptional properties of the sealing film: (1) the sealing film can be crosslinked in $30 \mathrm{~min}$, which was conducive to rapidly covering the coring. (2) $\mathrm{O}_{2}$ and water vapor permeability and light transmittance were reduced by $81.2 \%, 84.4 \%$, and $100 \%$, respectively, compared with pure silicone rubber. (3) The mechanical and thermal stability of the sealing film was impressive, which showed that the elongation at break was $98.0 \%$, the tensile strength was $0.857 \mathrm{MPa}$, and the thermal decomposition temperature was $240^{\circ} \mathrm{C}$. In addition, we designed a quality-preserving coring simulator, and the quality-preservation effect of the core with the sealing film was verified.

\section{Mechanism of In Situ Film-Forming}

In light of the deep in situ quality-preserving coring method, the mechanism of in situ film-forming is based on the principle of crosslinking. The polycondensation reaction of organosilicon is utilized as the film-forming mechanism, which was expressed as hydrolysis of crosslinking agent under the condition of water and reaction with matrix under the action of catalyst. However, the thermal stability temperature of catalyst and crosslinking agent is below $200^{\circ} \mathrm{C}$. So, within $200^{\circ} \mathrm{C}$, higher temperature is beneficial for diffusion of the water through the film and acceleration of the polymerization. As shown in Figure 1, when the filmforming polymer solution surrounding the rock core specimen is in contact with water, the linear polymer chains polymerize and crosslink rapidly under the action of the catalyst, in which a solid sealing film with excellent mechanical and barrier properties and being like a "cling film" is formed.

During sample drilling, the film-forming polymer solution with good fluidity will be filled into the gap between the core sleeve and core. Then, a polymerization and crosslinking reaction takes place on the core surface, to obtain an in situ sealing film in the narrow space of the coring device. Figure 2 shows the specific process of the quality-preserving coring method. First, solution B (water) is filled into the core sleeve while the drilling fluid flows down 


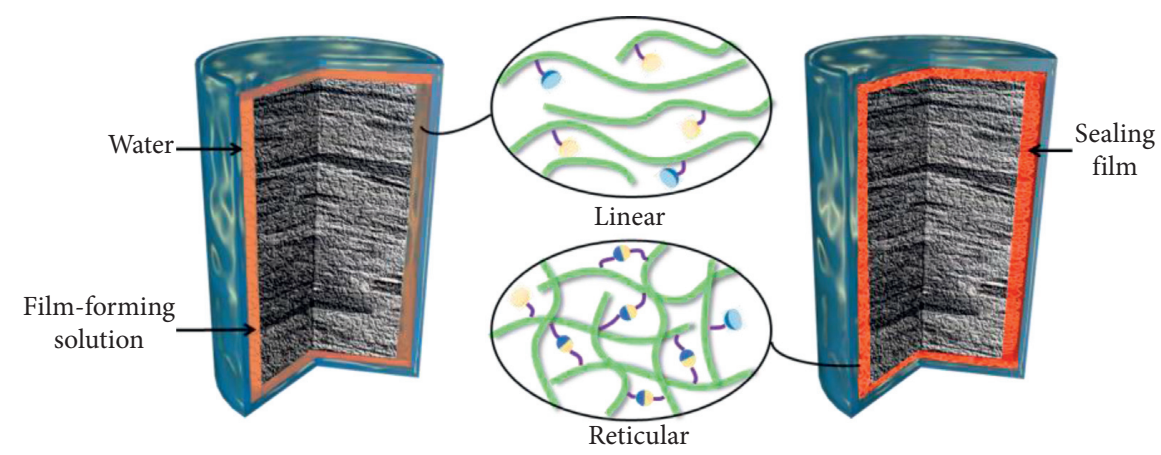

FIgURE 1: Schematic of in situ crosslinking film-forming mechanism.
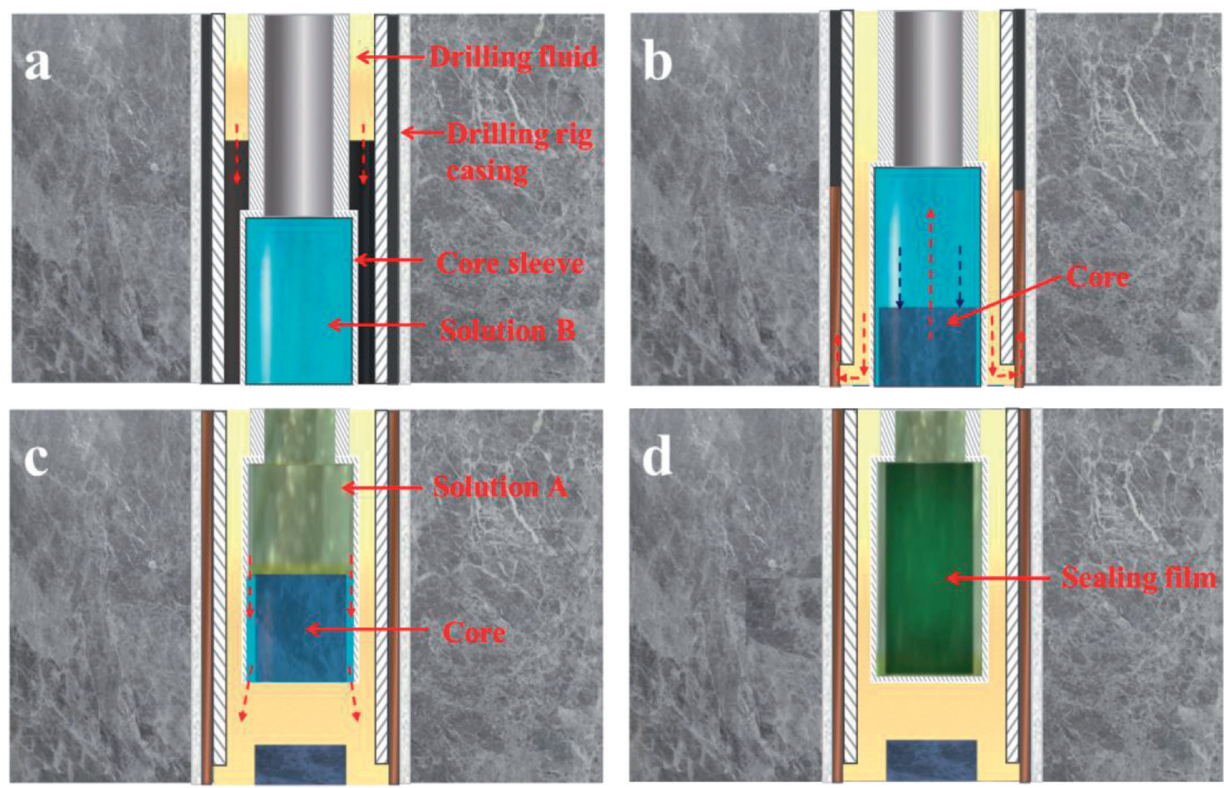

FIGURE 2: Schematic of the in situ crosslinking film-forming coring method: (a) drilling process; (b) before coring; (c) during coring; (d) after coring.

(Figure 2(a)). When the coring starts, the core enters the core sleeve slowly (Figure 2(b)), and solution A (film-forming solution) is injected into the core sleeve to cover the core (Figure 2(c)). Finally, the film-forming solution turns into a solid sealing film through the crosslinking reaction under the water condition (Figure 2(d)), which is an essential component for the preservation of the quality and moisture of the specimen and the blocking of light for the rock specimen.

\section{Characterization of OMMT Functional Nanofillers}

The material design and preparation are the key parts of the quality-preserving coring because they determine whether the sealing film has the ability to adapt to deep earth environments. Many researchers have reported that 2D nanolayers are beneficial in improving the mechanical and chemical properties of a nanocomposites [27, 28]. Hence, 2D lamellar nanosheets of sodium montmorillonite (Na-MMT) have been selected as a functional additive for sealing films. Na-MMT was modified to OMMT by cetyltrimethylammonium bromide $(\mathrm{CTAB})$ via an ion exchange process. The incorporated alkyl chain expanded the layer space and strengthened the compatibility of OMMT with the polymer matrix.

To confirm the intercalation of CTAB into OMMT, Fourier transform infrared (FTIR) measurements were performed. Figure 3 shows the FTIR spectra of Na-MMT and OMMT. The adsorption peaks at $1038 \mathrm{~cm}^{-1}$ and between 3620 and $3650 \mathrm{~cm}^{-1}$ were assigned to Si-O stretching and $-\mathrm{OH}$ stretching, respectively. The -OH adsorption peak can be attributed to the water adsorbed between the layers. The adsorption at $1640 \mathrm{~cm}^{-1}$ corresponds to sodium and that at $2930 \mathrm{~cm}^{-1}$ is due to $\mathrm{C}-\mathrm{H}$ bending vibrations. The disappearance of the sodium peak at $1640 \mathrm{~cm}^{-1}$ and the appearance of the $\mathrm{C}-\mathrm{H}$ peak suggest that Na-MMT is successfully modified by CTAB. In addition, the - $\mathrm{OH}$ peak is blue shifted after modification, indicating a reduced hydrophilic characterization.

Montmorillonite is composed of an aluminum oxide octahedron and a silicon oxide tetrahedron; sodium ions are absorbed between layers and can easily be exchanged with 


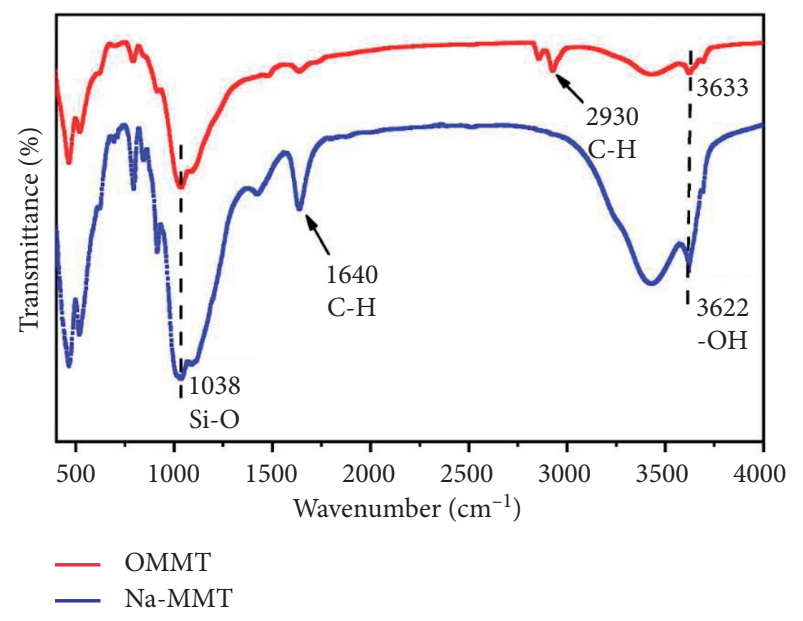

Figure 3: FTIR spectra of Na-MMT and OMMT.

other cations [29], so alkyl chains with cations are always utilized in modifying Na-MMT. The intercalation of small molecules into 2D layered structure or exfoliation of 2D structure generate strong XRD signals [30,31]. Accordingly, the $\mathrm{d}$-spacing of Na-MMT and OMMT was measured by $\mathrm{XRD}$, and the associated spectrums are shown in Figure 4. According to Bragg Law, Na-MMT shows a broad reflection peak (001) at $2 \theta=7.30^{\circ}$, which suggests that the d-spacing $\left(d_{001}\right)$ of Na-MMT is $1.21 \mathrm{~nm}$. For OMMT, a strong reflection peak appears at $2 \theta=4.7^{\circ}$, so the d-spacing $\left(d_{001}\right)$ is $1.88 \mathrm{~nm}$, which is 1.54 times that of Na-MMT. OMMT has a longer layer spacing, contributing to good exfoliation in the matrix, as well as better compatibility, resulting in excellent dispersion, than Na-MMT.

Figure 5 shows the microstructural morphologies of the OMMT obtained by scanning electron microscopy (SEM). From Figure 5(a), it can be observed that the OMMT sieved through a 200 mesh has different sizes and is easy to agglomerate, leading to the use of dispersion and distribution methods of solvent, shear, or high speed when composites with polymers are used. Figure 5(b) shows the magnified structure of OMMT. From the figure, it can be seen that the OMMT has a lamellar structure, with a thinner thickness, longer diameter, and larger specific surface area, indicating its suitability as a functional nanofiller to improve the quality- and moisture-preservation performance of the film. Figure 5(c) shows a higher magnification image of the OMMT. It can be seen that the OMMT has a rough surface with a large number of particles, which may be attributed to the CTAB adsorption on the OMMT surface or the exchange with the sodium ions, further confirming that the $\mathrm{CTAB}$ successfully modifies Na-MMT.

Thermal stability of OMMT was investigated by thermogravimetry as shown in Figure 6. The water molecules in OMMT started to be lost above the room temperature, and there are no changes in structure of OMMT. The initial temperature of thermal degradation is at $225^{\circ} \mathrm{C}$, and the alkyl chain of OMMT is decomposed completely at $460^{\circ} \mathrm{C}$, which means that the OMMT can maintain the relatively stability under $225^{\circ} \mathrm{C}$.

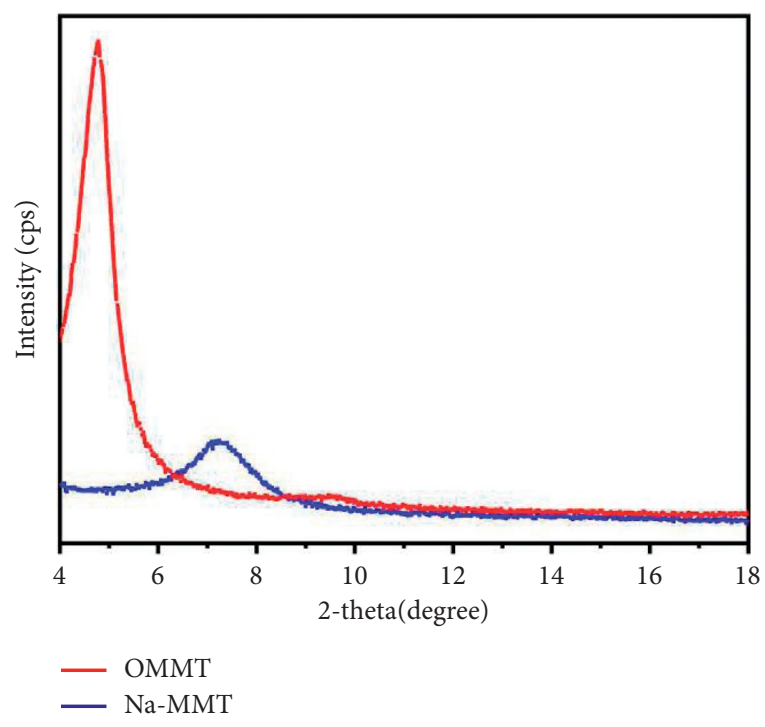

Figure 4: XRD patterns of Na-MMT and OMMT.

\section{Performance of Sealing Film}

A sealing film with good barrier and mechanical properties is required to surround the core of deep in situ rocks to preserve the properties of the rock. As previously mentioned, for specific applications, the disturbance during coring should be minimized and thermal stability should be maximized. In this study, we used polymer matrix, functional fillers, and a catalyst to prepare the sealing films. To further verify the properties of the sealing film, the testing of crosslinking time and permeability, and mechanical and thermal testing were performed.

4.1. Testing of Crosslinking Time. Considering the technical requirements of fast film-forming kinetics in the deep coring process, we argue that it is reasonable to control the crosslinking time within $30 \mathrm{~min}$. Figures $7(\mathrm{a})$ and $7(\mathrm{~b})$ show plots of the crosslinking time as a function of the catalyst content and temperature, respectively. It can be seen that, at the same temperature, a higher catalyst content leads to a shorter crosslinking time. In the reaction process, -Sn from the catalyst combines with hydroxyl oxygen, to form a complex compound and reducing the reaction activation energy and accelerating the crosslinking reaction time. In particular, when the catalyst content increases above $2.5 \mathrm{wt} \%$, the crosslinking time remains between 0 and $30 \mathrm{~min}$, and this may be because of the saturation of the interaction between the catalyst and crosslinker and the reaction rate remaining at the peak value; therefore, the catalyst content is no longer a strong factor affecting the crosslinking time. On the other hand, as shown in Figure 7(b), at the same catalyst content, the crosslinking time decreases as the temperature increases. The increase in temperature causes an acceleration of the migration rate of water vapor between air and the film or an increase in the content of water vapor, which accelerates the reaction rate and shortens the crosslinking time.

Crosslinking time testing is one of the basic parameters in accessing engineering application of in situ film-forming technology, from which researchers are able to utilize the 

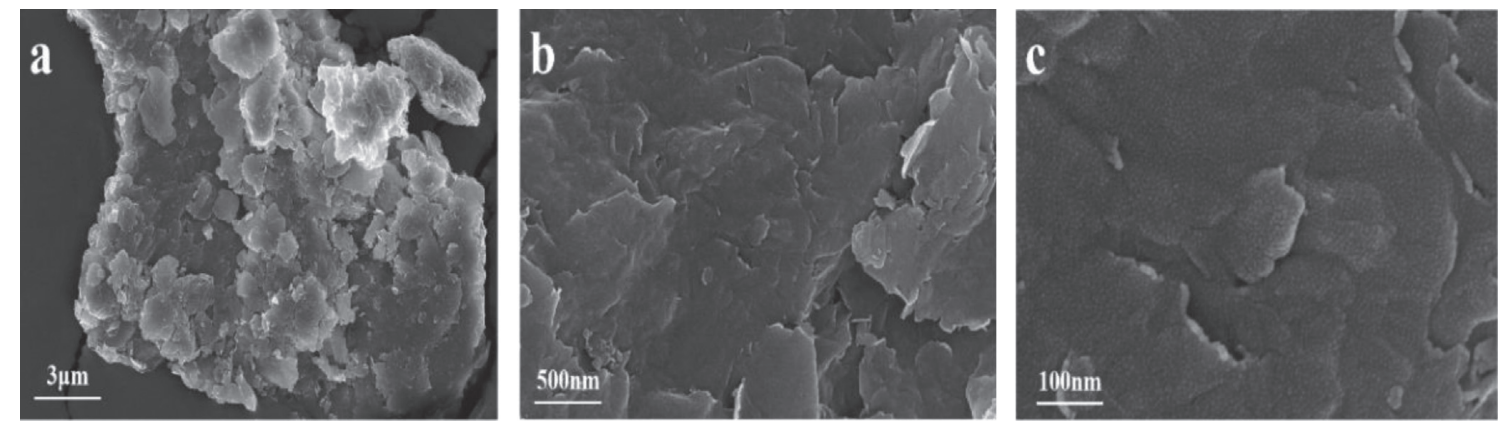

FIGURE 5: SEM images of the OMMT: (a) $3 \mu \mathrm{m}$, (b) $500 \mathrm{~nm}$, and (c) $100 \mathrm{~nm}$ scale bar.

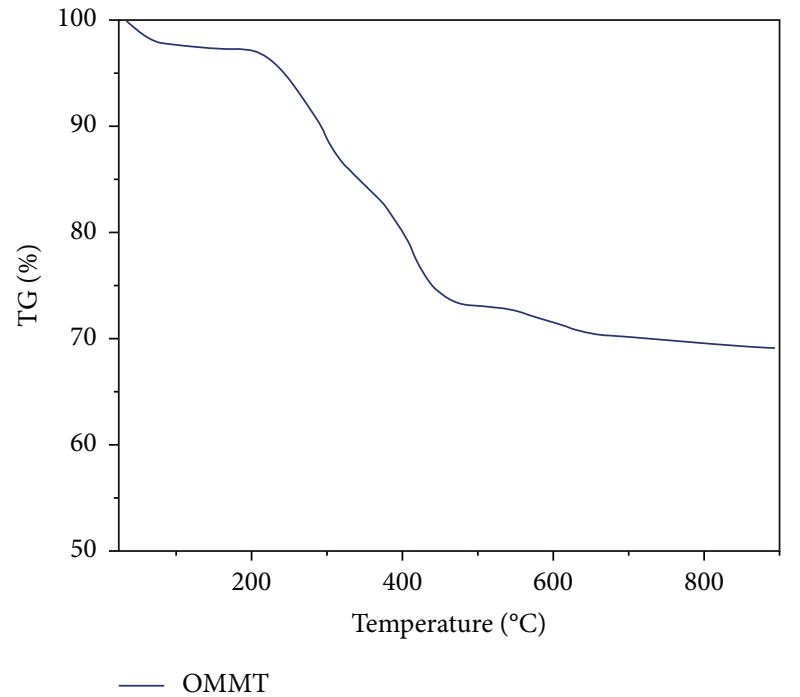

FIgURE 6: TGA curves of OMMT.

proper catalyst content in different temperature sections. In the low-temperature region $\left(25-100^{\circ} \mathrm{C}\right)$, the catalyst content has a stronger effect on the crosslinking time than the temperature. It can be seen that the addition of $0.25 \mathrm{wt} \%$ catalyst can sharply reduce the crosslinking time, while the temperature has to increase to $70^{\circ} \mathrm{C}$ at least for the same effect. At higher temperatures $\left(100-200^{\circ} \mathrm{C}\right)$, both the catalyst and temperature have a positive effect on the reduction of the crosslinking time.

4.2. Testing of Molecular Permeability and Light Transmittance. Quality and moisture preservation and lightproof are the most important properties of sealing films, as they determine how well the matter transfer can be prevented between the external and internal parts of the core. Incorporating $2 \mathrm{D}$ nanosheets is the most efficient method to improve the gas and moisture barrier properties in situ in a narrow space [32]. Figure 8 shows a schematic of the gas molecule diffusion. The method of incorporating 2D nanosheet mainly depends on the uniform dispersion and distribution of the lamellar nanofillers in the matrix polymers; these determine the orientation of the structure, which cause the gas or moisture molecules to form a tortuous path through the "barrier effect" of nanofillers and increases the path length, leading to a lower permeability of the sealing film [33]. Many researchers, including Nielsen [34], Bharadwaj [35], Gusev and Lusti [36], Lape et al. [37], and Fredrickson and Bicerano [38], have established various theoretical models to describe the molecular barrier mechanism of planar sealing films.

Figure 9 (a) shows a plot of the gas $\left(\mathrm{O}_{2}\right)$ permeability of the composite film as a function of the OMMT content. Owing to the strong interfacial interactions between OMMT and the silicone rubber and the excellent dispersion, the formation of a complex nanofiller network comprising OMMT nanosheets significantly increases the diffusion path of the $\mathrm{O}_{2}$ molecules. The sealing film exhibits a permeability much lower than that of pure silicone rubber. Overall, the $\mathrm{O}_{2}$ permeability decreases with increasing nanofiller content. At an OMMT filler content of $2 \mathrm{wt} \%$, the $\mathrm{O}_{2}$ permeability sharply reduces to $5.28 \times 10^{-5} \mathrm{~m}^{3} \mathrm{~m} / \mathrm{m}^{2} \cdot \mathrm{d} \cdot 0.1 \mathrm{MPa}$, and as the filler content increases further, the $\mathrm{O}_{2}$ permeability decreased relatively slowly. In addition, the $\mathrm{P} / \mathrm{P}_{0}$ ratio decreases sharply to $58.6 \%$ when the OMMT content is $2 \mathrm{wt} \%$, and then slowly decreases to $18.8 \%$ at the $32 \mathrm{wt} \%$ content. The $\mathrm{O}_{2}$ permeability decreases by approximately $81.2 \%$ when $32 \mathrm{wt} \%$ OMMT is added. This is highly beneficial for preventing the escape of various types of volatile matters from the core during drilling.

The deep earth core contains a large number of ionic compounds, which are useful for analyzing the components of the deep earth environment and the mechanism of geological rock formation; thus, the preservation of the quality of the specimens is crucial for deep earth coring. To further confirm the quality-preservation performance of the sealing film, the calcium ion permeability of the $32 \mathrm{wt} \%$ OMMT/silicone rubber composite has been tested, and the results are shown in Figure 9(b). It can be seen that the calcium ion concentration remains stable at approximately $6.3 \mathrm{mg} / \mathrm{L}$, suggesting that only a few calcium ion are transported from one side of the sealing film to the other. This phenomenon is attributed to the compact micromorphology, the hydrophobicity of the sealing film, and the tortuosity of the path due to the OMMT nanosheets.

The moisture-preservation performance of sealing film is also crucial property of the sealing film, which benefits to protect the pore-water of the in situ core, to further evaluate the resources accurately and obtain the in situ mechanical parameters. Figure 9(c) shows plots of the water vapor permeability as a function of the OMMT content. It can be seen that the water vapor permeability decreases as the OMMT content increases. With an the 


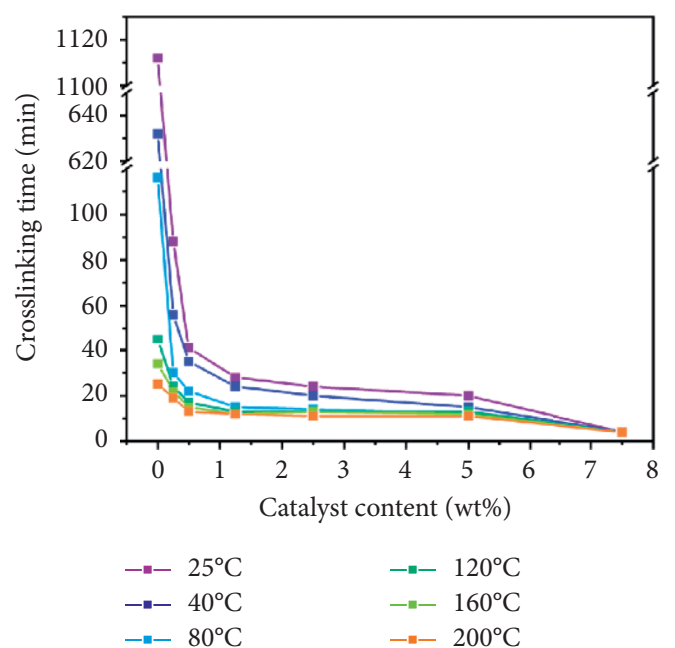

(a)

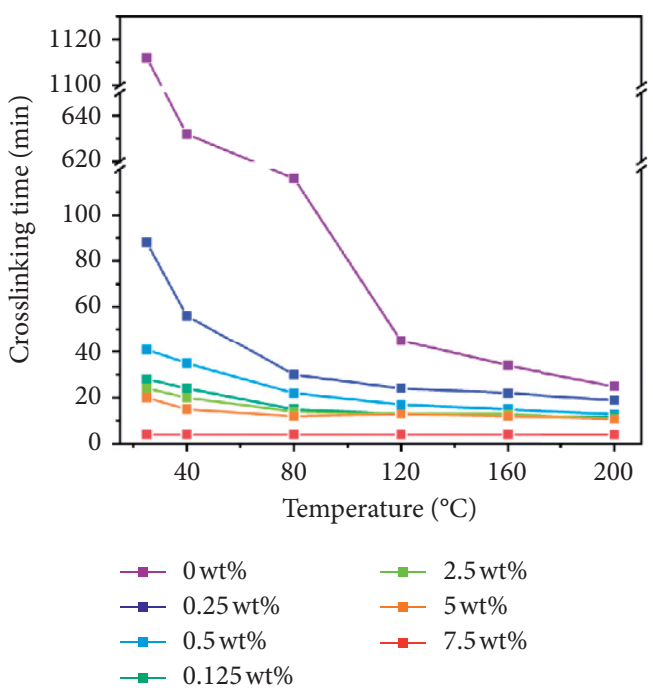

(b)

FIgURE 7: Plot of the crosslinking as a function of (a) the catalyst content and (b) temperature.

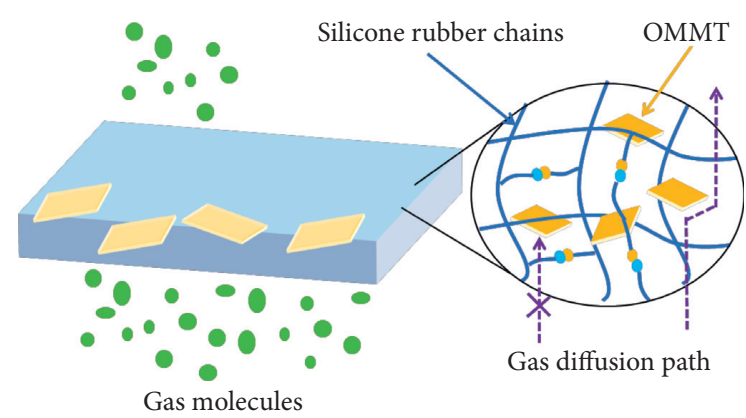

Figure 8: Schematic of gas molecule diffusion in sealing film.

OMMT content of $20,24,28$, and $32 \mathrm{wt} \%$, the water vapor permeability is $1.97 \times 10^{-2}, 1.24 \times 10^{-2}, 1.08 \times 10^{-2}$, and $0.594 \times 10^{-2} \mathrm{~g} \mathrm{~m} / \mathrm{m}^{2} \cdot \mathrm{d}$, which is $51.9 \%, 32.7 \%, 28.5 \%$, and $15.6 \%$ that of pure silicone rubber, respectively. The water vapor molecules also follow the diffusion theory; thus, the OMMT nanosheets greatly contribute to reducing the water vapor permeability.

If the core is exposed to light during coring, microorganisms living in the rock may die. Therefore, to accurately analyze the microorganisms living deep in the earth, a lightproof sealing film has to be developed to protect the core from the light. CB is a common functional filler for light absorption. In this study, we investigate the relationship between the lightproof performance of the film and the CB content. As shown in Figure 9(d), a small amount of CB can induce excellent visible light absorption properties. The addition of $0.05 \mathrm{wt} \% \mathrm{CB}$ leads to a sharp decrease in light transmittance to $19.3 \%$. When the $\mathrm{CB}$ content is increased to $0.2 \mathrm{wt} \%$, the sealing film behaves as a complete light-proof composite.

4.3. Mechanical and Thermal Stability Properties. During coring, the sealing film is subject to the pulling action and mechanical disturbance; thus, the sealing film must possess good mechanical properties. Figure 10 shows the representative stress-strain curves of the sealing films that exhibited good gas barrier properties. It is evident that the sealing film with OMMT and CB is mechanically stable (as shown in Table 1), which is determined from the good dispersion of fillers in the sealing film. The average stress on the sealing film is $0.857 \mathrm{MPa}$. This is due to the fact that the polymer chains entangle around the fillers and form a physical crosslinking structure, which can better resist external forces. Furthermore, the sealing film possesses high flexibility, with an average elongation at a break of $98.0 \%$, which is advantageous for adapting to the complex environment of the deep earth.

The temperature of the ground towards the core of the earth increases by $3 \mathrm{C}$ every $100 \mathrm{~m}$. Therefore, the sealing film must withstand various temperature conditions underground. To verify the thermal stability of the sealing film, a thermogravimetric analysis (TGA) was performed, and the results are reported in Figure 11. In the initial heating period $\left(25-240^{\circ} \mathrm{C}\right)$, the weight of the sealing film does not change significantly, indicating a good heat resistance, which is attributed to the high $\mathrm{Si}-\mathrm{O}$ bond energy and crosslinking structure. Then, the weight gradually decreases until the weight loss rate reaches the peak at $500^{\circ} \mathrm{C}$ and plateaus at $580^{\circ} \mathrm{C}$. Finally, at approximately $740^{\circ} \mathrm{C}$, the sealing film fully decomposes except for the inorganic filler components.

\section{Engineering Application of In Situ Film- Forming}

5.1. Development of Quality-Preserving Coring Simulator. To verify the in situ film-forming mechanism and qualitypreserving coring methods, it is significantly necessary to develop a set of quality-preserving coring simulation device. The design concept of the simulator is shown in Figure 12. This device is mainly composed of a putter, righting slide sleeve, spring sleeve, core sleeve, and core 


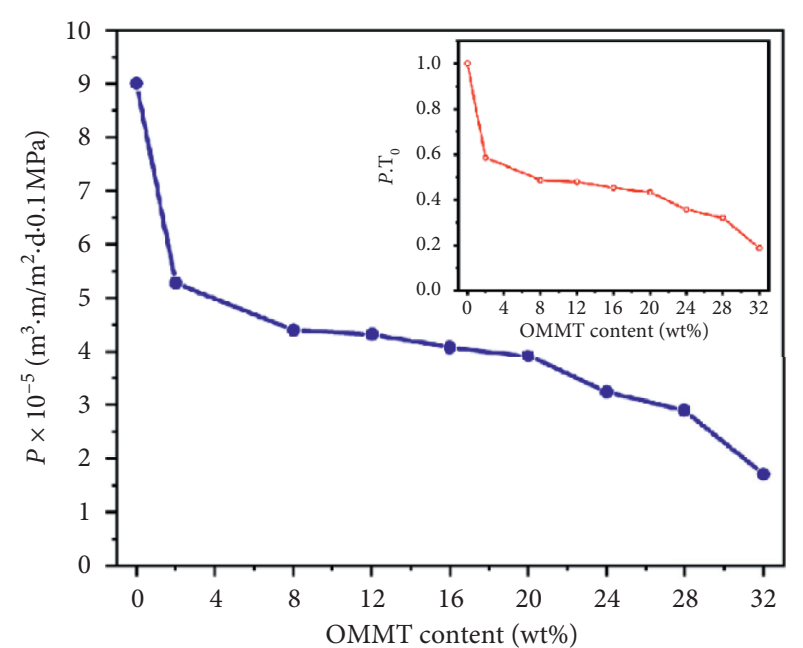

(a)

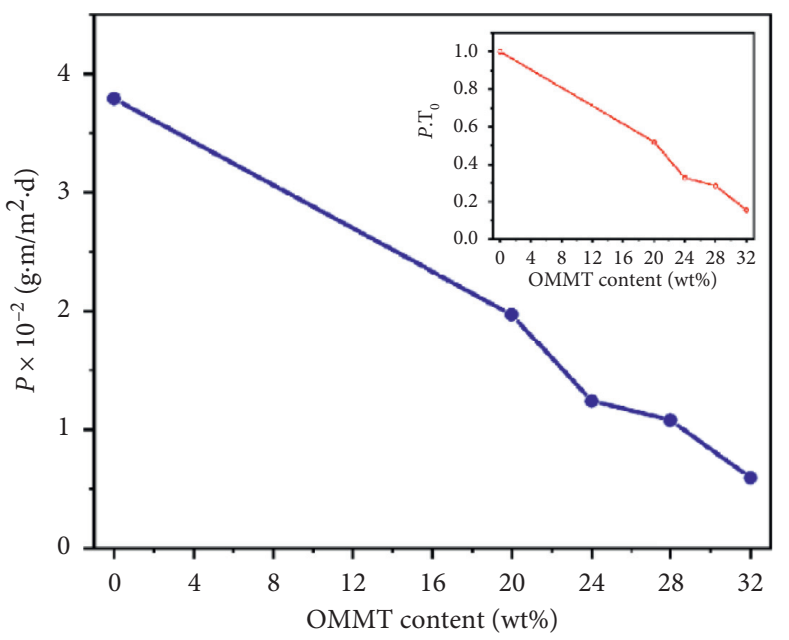

(c)

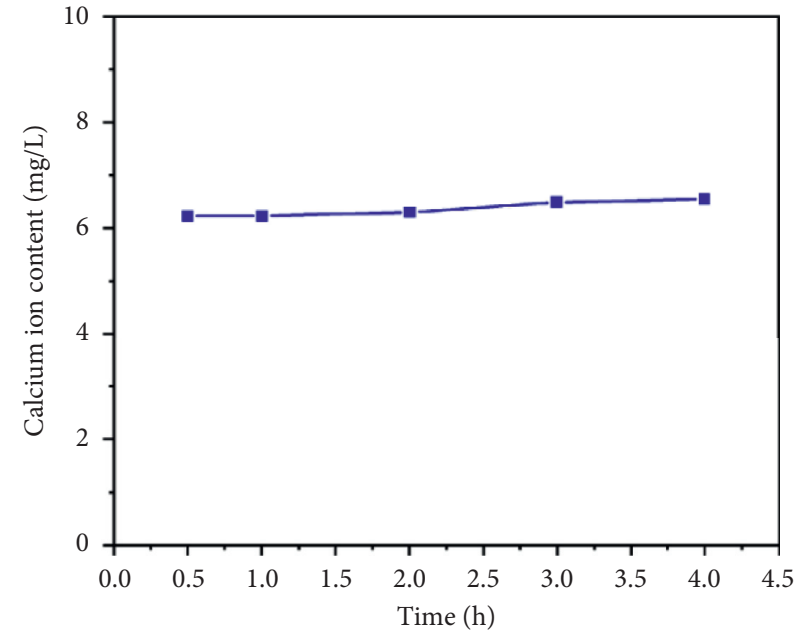

(b)

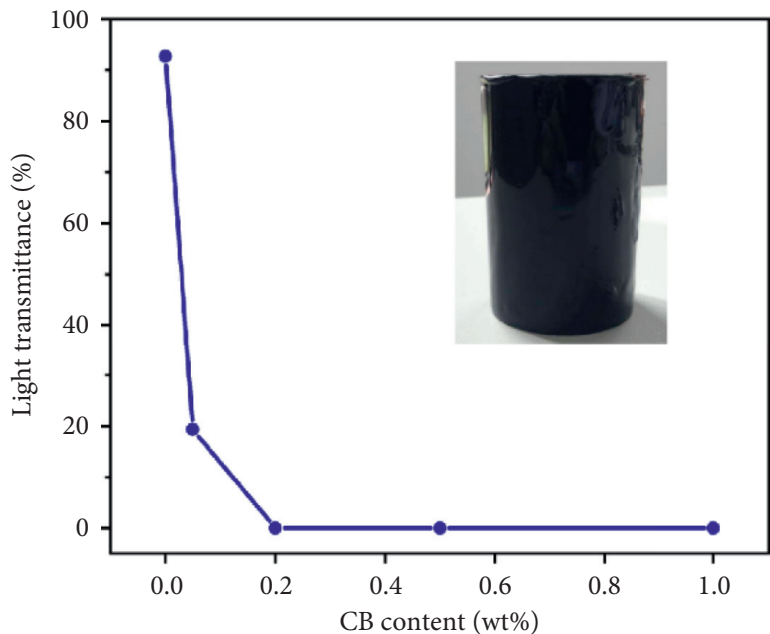

(d)

FIGURE 9: Molecule barrier property of the sealing film: (a) $\mathrm{O}_{2}$ permeability; (b) calcium ion permeability; (c) water vapor permeability; (d) light transmittance.

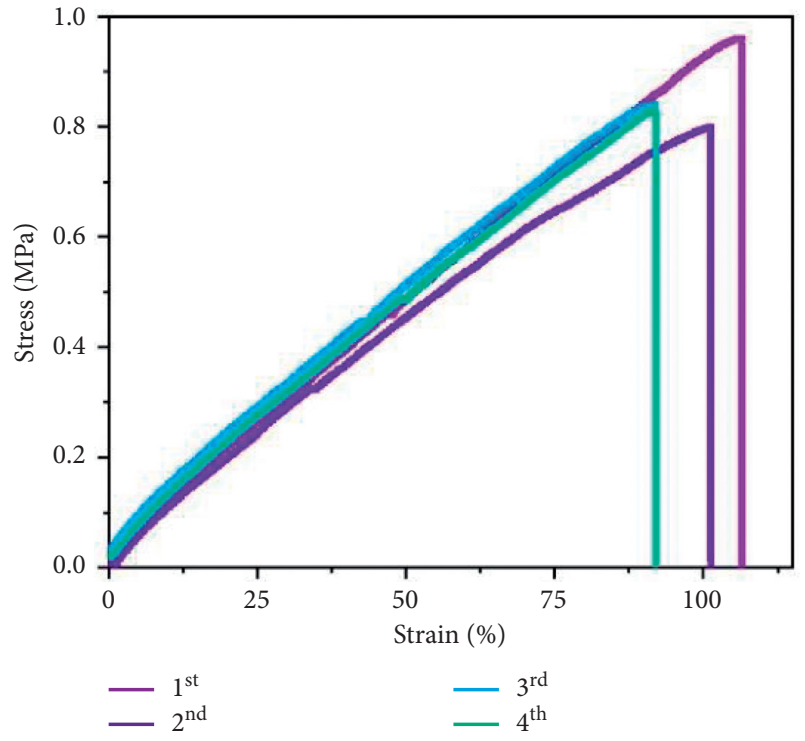

FIGURE 10: Stress-strain curve of the sealing films.
TABLE 1: Strain and stress of sealing films.

\begin{tabular}{lccccc}
\hline & $1^{\text {st }}$ & $2^{\text {nd }}$ & $3^{\text {rd }}$ & $4^{\text {th }}$ & Average \\
\hline Strain (\%) & 106.5 & 101.3 & 92.1 & 92.1 & 98.0 \\
Stress (MPa) & 0.96 & 0.80 & 0.84 & 0.83 & 0.857 \\
\hline
\end{tabular}

(Figure 12(a)). The operation of device involves four steps. Firstly, before coring, the core is confined between the righting sliding sleeve and the sealing ring, and the entire space is filled with water to simulate the in situ groundwater environment. Secondly, the core is pushed upward into the core sleeve, which is filled with water, to simulate the process of coring (Figure 12(b)). Thirdly, the filmforming solution is injected into the core sleeve from the injection hole to drain the water and completely coat the core, which simulates the process of core coating with the film-forming solution (Figure 12(c)). Fourthly, the crosslinking and curing reaction of the film-forming solution take places under the action of water and a sealing film is formed covering the core (Figure 12(d)). Figure 13(a) 


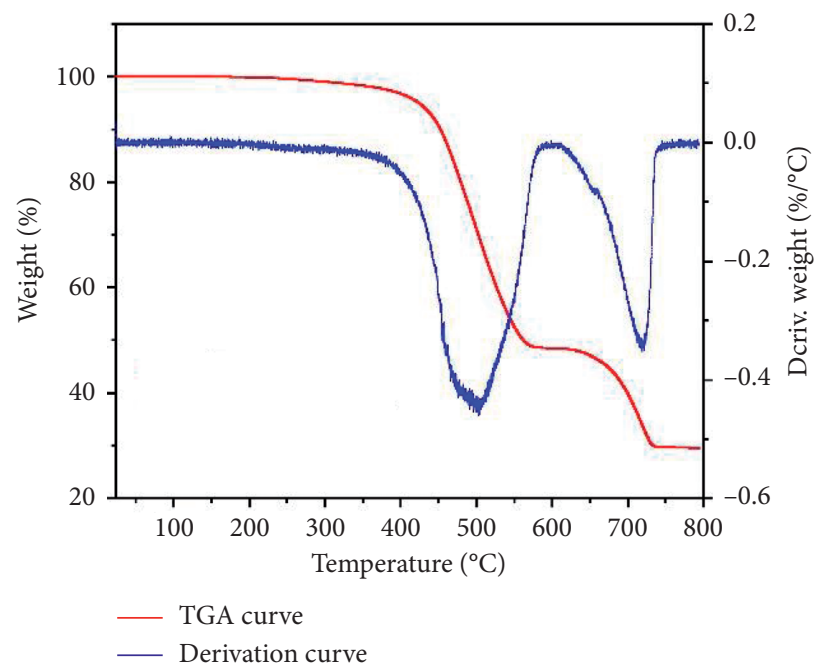

FIgURE 11: TGA thermo gram results of sealing film with a temperature increase rate of $10 \mathrm{~min} /{ }^{\circ} \mathrm{C}$ in $\mathrm{N}_{2}$ atmosphere.

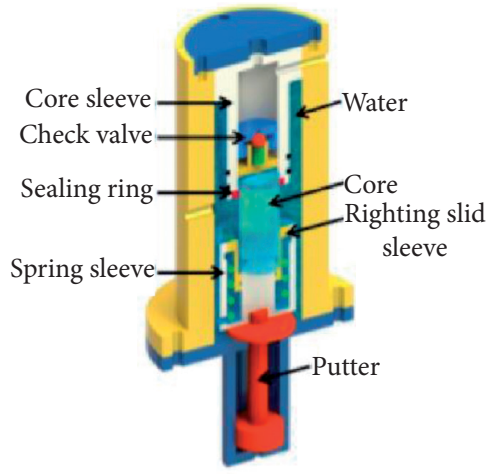

(a)

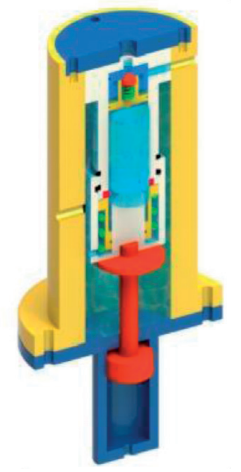

(b)

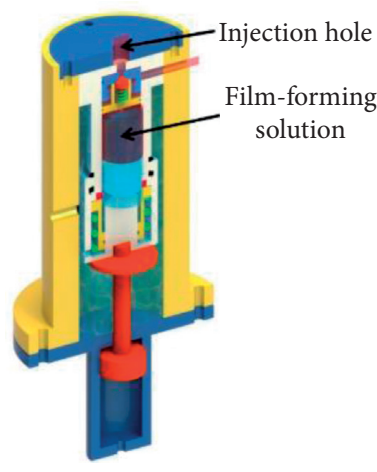

(c)

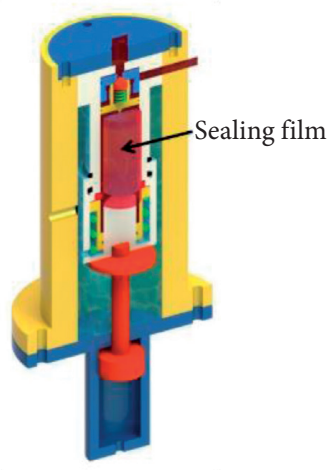

(d)

FIGURE 12: Schematic of the quality-preserving coring simulator operation: (a) before coring; (b) after coring; (c) core covered with filmforming solution; (d) crosslinking process.

shows a photograph of the quality-preserving coring simulator, and Figure 13(b) shows a photograph of the core coated with the sealing film, which displays a complete and smooth coating surface.

\subsection{Verification of Quality-Preserving Ability of the Sealing} Film. To further verify the quality-preservation ability of the sealing film, the calcium ion concentration and water vapor transmission experiments were calibrated. Two core samples, filled with either a saturated calcium chloride solution or deionized water, were covered with a sealing film. One of the samples was first filled with saturated calcium chloride solution and covered with the sealing film and then placed in deionized water. The other pure sample was filled with saturated calcium chloride solution but was not covered with the film and was placed in deionized water as a reference sample. Figure 14 shows the change in the calcium ion concentration of the samples over time. After $300 \mathrm{~min}$ of immersion, only $0.04 \mathrm{gm} / \mathrm{L}$ of calcium ions migrated into the deionized water from the sample covered with sealing film, while approximately $0.6 \mathrm{mg} / \mathrm{L}$ calcium ions migrated into the deionized water from the pure sample. This suggests that the sealing film prevents the loss of calcium ions from the core.

Pore-water has a great influence on the mechanical properties of rocks. In order to study the impact of in situ water on rocks, it is necessary to master the distribution and diffusion path of in situ water in rocks. So, keeping the in situ state of the water is significantly important. The sealing film is able to prevent the pore-water being lost from the internal of the rocks, and also could keep the external water away from the rocks. Therefore, the sealing film is beneficial for exploring the influence of water on in situ rock mechanics. Figure 15 shows the internal water weight loss of the core samples with and without sealing film. The weight curve of the sample covered with the sealing film is relatively smooth, and the value of weight loss was about $2.48 \mathrm{~g}$, which did not change significantly with the temperature and humidity. However, the curve of pure sample changed irregularly and the value of weight loss was about $6.55 \mathrm{~g}$, which was 2.64 times of value of sample covered with sealing film. We believed that the sealing film with water vapor barrier property could prevent the transport and migration of water molecules between the internal and external parts of the 


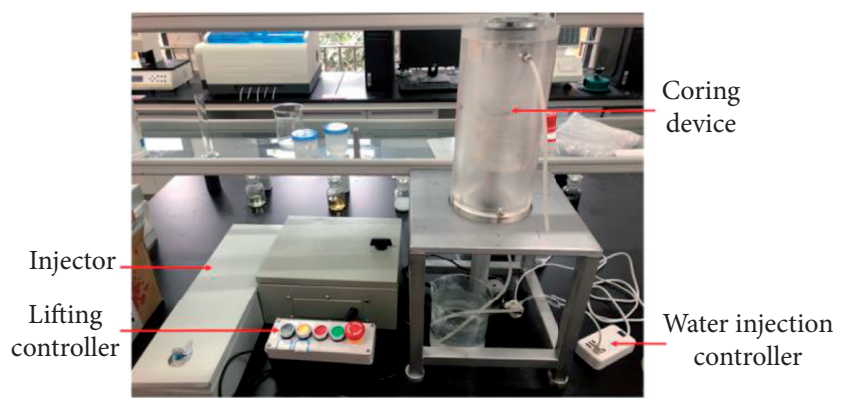

(a)

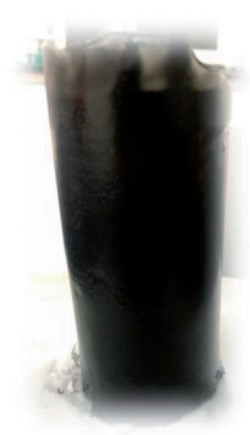

(b)

FIGURE 13: Photograph of (a) quality-preserving coring simulator and (b) core covered with sealing film.

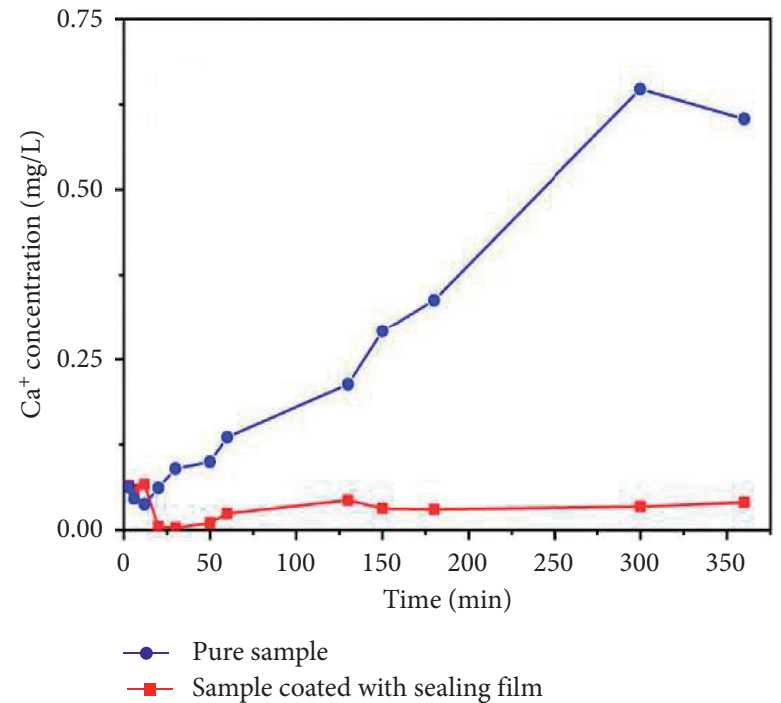

Figure 14: Plot of calcium ion concentration over time of the samples with and without sealing film.

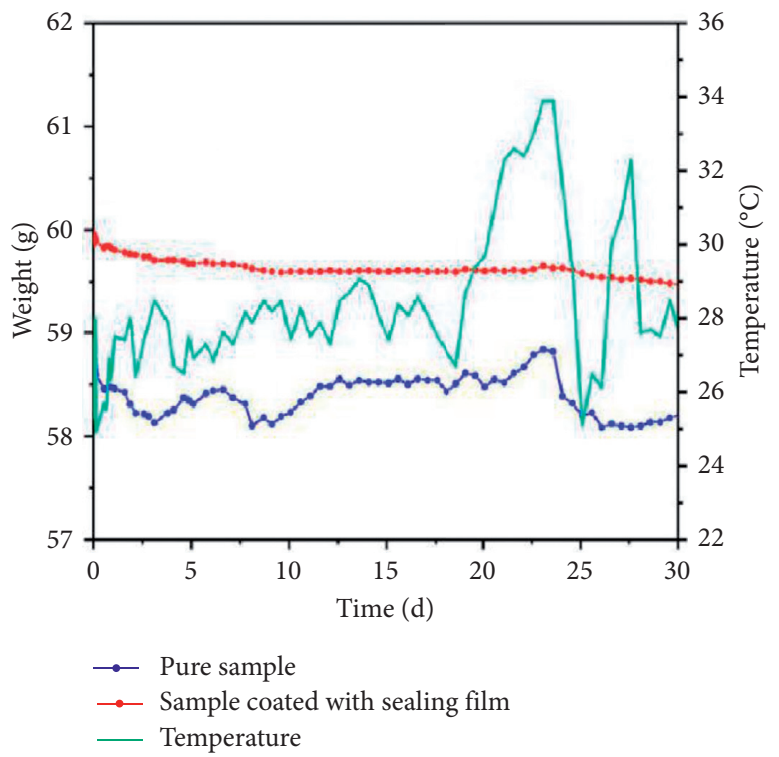

(a)

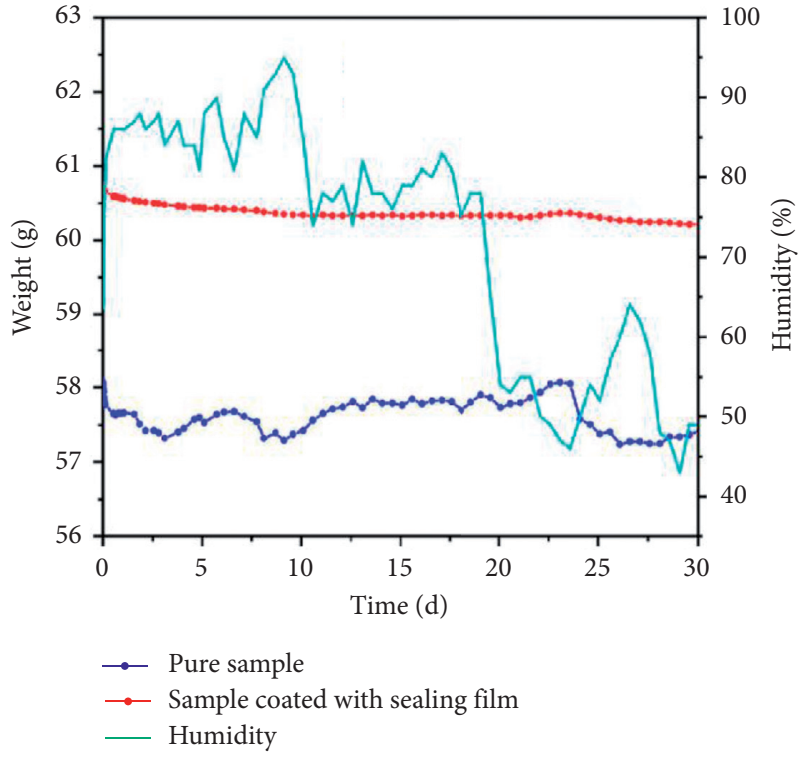

(b)

FIGURE 15: Plot of water vapor transmission as a function of (a) temperature and (b) humidity of the samples with and without sealing film. 
core, even if under the change condition of temperature and humidity.

\section{Conclusion}

We developed a solid film method for quality-preservation coring of deep rocks. The film allows the preservation of the quality and moisture of the core, as well as blocking of the external light. In this method, a film-forming solution is deposited on the core and the sealing film is formed through crosslinking reaction. The sealing films exhibited good molecule barrier performance and mechanical and thermal stability within 20 min of crosslinking. A coring simulator was developed to test the quality-preservation ability of the sealing film. The results showed that the core covered with the sealing film did not lose significant amounts of calcium ions and moisture. The results of this study demonstrated that the method developed may open up new opportunities for studying of deep earth resources and construction of deep in situ rock mechanics.

\section{Data Availability}

The raw/processed data required to reproduce these findings cannot be shared at this time as the data also form part of an ongoing study.

\section{Conflicts of Interest}

The authors declare that they have no conflicts of interest.

\section{Acknowledgments}

This study was funded by the National Natural Science Foundation of China (grant no. 51827901) and Science and Technology Department of Sichuan Province (grant no.2020YFH0012)

\section{References}

[1] H. Xie, F. Gao, and Y. Ju, "Research and development of rock mechanics in deep ground engineering," Chinese Journal of Rock Mechanics and Engineering, vol. 34, no. 11, pp. 21612178, 2015.

[2] M. Gao, S. Zhang, J. Li, and H. Wang, "The dynamic failure mechanism of coal and gas outbursts and response mechanism of support structure," Thermal Science, vol. 23, no. Suppl 3, p. 122, 2019.

[3] M. Gao, Z. Zhang, Y. Xiangang, C. Xu, Q. Liu, and H. Chen, "The location optimum and permeability-enhancing effect of a low-level shield rock roadway," Rock Mechanics and Rock Engineering, vol. 51, pp. 2935-2948, 2018.

[4] F. Gong, W. Wu, T. Li, and X. Si, "Experimental simulation and investigation of spalling failure of rectangular tunnel under different three-dimensional stress states," International Journal of Rock Mechanics and Mining Sciences, vol. 122, Article ID 104081, 2019.

[5] F.-Q. Gong, X.-F. Si, X.-B. Li, and S.-Y. Wang, "Experimental investigation of strain rockburst in circular caverns under deep three-dimensional high-stress conditions," Rock $\mathrm{Me}$ chanics \& Rock Engineering, vol. 52, no. 4, pp. 1459-1474, 2018.
[6] T. Litt, S. Krastel, M. Sturm et al., “PALEOVAN', international continental scientific drilling program (ICDP): site survey results and perspectives," Quaternary Science Reviews, vol. 28, no. 15-16, pp. 1555-1567, 2009.

[7] C. S. Sturm, K. G. Miller, A. W. Droxler, S. P. Hesselbo, G. F. Camoin, and M. A. Kominz, "Drilling to decipher longterm sea-level changes and effects-a joint consortium for ocean leadership, ICDP, IODP, DOSECC, and chevron workshop," Scientific Drilling, vol. 6, no. 6, pp. 19-28, 2008.

[8] L. R. Coney, U. G. Wolf, L. Roger, and C. Koeberl, "Geochemistry of impactites and basement lithologies from ICDP borehole LB-07A, Bosumtwi impact structure, Ghana," Meteoritics \& Planetary Ence, vol. 42, no. 4-5, pp. 667-688, 2015.

[9] Y. T. Sup, "Mechanical and thermal study of hydrate bearing sediments," Dissertations \& Theses, Georgia Institute of Technology, Atlanta, GA, USA, 2005.

[10] J. Osborne, G. Yetginer, T. Halliday, and T. I. Tjelta, "The future of deepwater site investigation: seabed drilling technology," in Proceedings of the Frontiers in Offshore Geotechnics II ISFOGA, p. 299, Perth, Australia, November 2010.

[11] L. Yang, Y. Liu, H. Zhang et al., "The status of exploitation techniques of natural gas hydrate," Chinese Journal of Chemical Engineering, vol. 27, no. 9, pp. 2133-2147, 2019.

[12] G. R. Dickens, P. J. Wallace, C. K. Paull, and W. S. Borowski, "Detection of methane gas hydrate in the pressure core sampler (PCS): volume-pressure-time relations during controlled degassing experiments," Proceedings of the Ocean Drilling Program: Scientific Results, vol. 164, pp. 113-126, 2000.

[13] A. V. Milkov, G. R. Dickens, G. E. Claypool et al., "Co-existence of gas hydrate, free gas, and brine within the regional gas hydrate stability zone at hydrate ridge (Oregon margin): evidence from prolonged degassing of a pressurized core," Earth and Planetary Science Letters, vol. 222, no. 3-4, pp. 829-843, 2004.

[14] H. Amann, H. Hohnberg, and R. Reinelt, "HYACE-a novel autoclave coring equipment for systematic offshore gas hydrate sampling," Deutsche Wissenschaftliche Gesellschaft für Erdgas und Kohle eV (DGMK), Report, vol. 9706, pp. 37-49, 1997.

[15] P. Schultheiss, M. Holland, and G. Humphrey, "Wireline coring and analysis under pressure: recent use and future developments of the HYACINTH system," Scientific Drilling, vol. 7, no. 4, pp. 151-163, 2009.

[16] K. A. Kvenvolden, L. A. Barnard, and D. H. Cameron, "Pressure core barrel: application to the study of gas hydrates, deep sea drilling project site 533, leg 76," Initial Reports of the Deep Sea Drilling Project, vol. 76, pp. 367-375, 1983.

[17] M Guiqing, X Yuzhi, H. Xinggui et al., "Development and application of a synthetic-based sealing fluid," Petroleum Drilling Techniques, vol. 34, no. 4, pp. 50-51, 2010.

[18] H. Xie, G. Zhang, and C. Li, "Scheme of underground space utilization of lunar thermostatic layer," Advanced Engineering Sciences, vol. 52, no. 1, pp. 1-8, 2020.

[19] H. Xie, M. Gao, R. Zhang, L. Chen, T. Liu, C. Li et al., "Study on concept and progress of in situ fidelity coring of deep rocks," Chinese Journal of Rock Mechanics and Engineering, vol. 39, no. 5, pp. 865-876, 2020.

[20] M. C. K. Swamy and Satyanarayan, "A review of the performance and characterization of conventional and promising thermal interface materials for electronic package applications," Journal of Electronic Materials, vol. 48, no. 12, pp. 7623-7634, 2019. 
[21] L. Bo, Properties and Kinetic Analysis of Room Temperature Vulcanized Methylethylisicone Rubber, Shandong university, Jinan, China, 2015.

[22] E.-H. Song, B.-H. Kang, T.-Y. Kim et al., "Highly oriented gold/nanoclay-polymer nanocomposites for flexible gas barrier films," ACS Applied Materials \& Interfaces, vol. 7, no. 8, pp. 4778-4783, 2015.

[23] F. Ding, J. Liu, S. Zeng et al., "Biomimetic nanocoatings with exceptional mechanical, barrier, and flame-retardant properties from large-scale one-step coassembly," Science Advances, vol. 3, no. 7, pp. 170-212, 2017.

[24] S. Xie, O. M. Istrate, P. May et al., "Boron nitride nanosheets as barrier enhancing fillers in melt processed composites," Nanoscale, vol. 7, no. 10, pp. 4443-4450, 2015.

[25] A. Eckert, T. Rudolph, J. Guo, T. Mang, and A. Walther, "Exceptionally ductile and tough biomimetic artificial nacre with gas barrier function," Advanced Materials, vol. 30, pp. 1-8, 2018.

[26] H. Ha, J. Park, K. Ha, B. D. Freeman, and C. J. Ellison, "Synthesis and gas permeability of highly elastic poly (dimethylsiloxane)/graphene oxide composite elastomers using telechelic polymers," Polymer, vol. 93, pp. 53-60, 2016.

[27] W. Liu, H. Li, J. Jin et al., "Synergy of epoxy chemical tethers and defect-free graphene in enabling stable lithium cycling of silicon nanoparticles," Angewandte Chemie International Edition, vol. 58, no. 46, pp. 16590-16600, 2019.

[28] D. W. Schaefer and R. S. Justice, "How nano are nanocomposites?” Macromolecules, vol. 40, no. 24, pp. 8501-8517, 2007.

[29] S. S. Ray and M. Okamoto, "Polymer/layered silicate nanocomposites: a review from preparation to processing," Progress in Polymer Science, vol. 28, no. 11, pp. 1539-1641, 2003.

[30] W. Liu, V. A. Tanna, B. M. Yavitt, C. Dimitrakopoulos, and H. Henning Winter, "Fast production of high-quality graphene via sequential liquid exfoliation," ACS Applied Materials \& Interfaces, vol. 7, no. 49, pp. 27027-27030, 2015.

[31] S. Z. Butler, S. M. Hollen, L. Cao et al., "Progress, challenges, and opportunities in two-dimensional materials beyond graphene," American Chemical Society Nano, vol. 7, no. 4, pp. 2898-2926, 2013.

[32] N. Yan, F. Capezzuto, M. Lavorgna et al., "Borate cross-linked graphene oxide-chitosan as robust and high gas barrier films," Nanoscale, vol. 8, no. 20, pp. 10783-10791, 2016.

[33] C. Wolf, H. Angellier-Coussy, N. Gontard, F. Doghieri, and V. Guillard, "How the shape of fillers affects the barrier properties of polymer/non-porous particles nanocomposites: a review," Journal of Membrane Science, vol. 556, pp. 393-418, 2018.

[34] L. E. Nielsen, "Models for the permeability of filled polymer systems," Journal of Macromolecular Science: Part A-Chemistry, vol. 1, no. 5, pp. 929-942, 1967.

[35] R. K. Bharadwaj, "Modeling the barrier properties of polymerlayered silicate nanocomposites," Macromolecules, vol. 34, no. 26, pp. 9189-9192, 2001.

[36] A. A. Gusev and H. R. Lusti, "Rational design of nanocomposites for barrier applications," Advanced Materials, vol. 13, no. 21, pp. 1641-1643, 2001.

[37] N. K. Lape, E. E. Nuxoll, and E. L. Cussler, "Polydisperse flakes in barrier films," Journal of Membrane Science, vol. 236, no. 12, pp. 29-37, 2004.

[38] G. H. Fredrickson and J. Bicerano, "Barrier properties of oriented disk composites," The Journal of Chemical Physics, vol. 110, no. 4, pp. 2181-2188, 1999. 